\title{
Império e "desimpério" - as questões de territorialidade em As naus de António Lobo Antunes
}

\section{Empire and "disempire" - questions of territoriality in António Lobo An- tunes' Return of the Caravels}

BÁLINT URBÁN [bacalhau84@gmail.com]

Eötvös Loránd Tudományegyetem, Hungria

\begin{abstract}
RESUMO:
As Naus (1988) de António Lobo Antunes é uma obra complexa que sintetiza em si as poéticas e as políticas da literatura pós-25 de Abril, mais especificamente aquelas tendências da ficção pós-revolucionária que tencionaram subverter as grandes narrativas míticas da portugalidade, desestabilizando assim o modelo da identidade secular. No centro do romance antuniano encontra-se a representação da impossibilidade e do colapso da narrativa do grande Império Português, como complexo espaço colonial e ultramarino que ao longo de 500 anos constituía a base da identificação e da legitimação culturais e políticas de Portugal. O presente estudo, partindo da descrição das características inerentes do espaço colonial e do grande Império Português, pretende traçar com a ajuda das noções do território e da territorialidade de Deleuze e Guattari como é que este espaço colonial se desconstrói e passa a ser substituído por um espaço citadino essencialmente rizomático.
\end{abstract}

\section{Palavras-chave:}

António Lobo Antunes; ficção pós-25 de Abril; pós-modernismo português; territorialidade; desconstrução do Império; cidade; rizoma; cidade rizomática

\begin{abstract}
:
António Lobo Antunes' outstanding novel, The Return of the Caravels synthesizes in itself in a quiet expressive manner both the poetics and the politics of the post-revolutionary Portuguese fiction. The novel is undoubtedly the very apex of those postmodern tendencies in Portugal that aimed to subvert, rewrite and to deconstruct a whole national imaginary based on certain mythical narratives. In Antunes' work the reader is confronted with the representation of the impossibility and of the collapse of a trans-historical master narrative. The concept of this narrative was constructed around the idea of the great Colonial Empire which constituted the legitimatizing ideology of a certain cultural identity model. This article focuses on two matters: firstly, it deals with the characterization of the Portuguese Colonial Empire and secondly, it focuses on its deconstruction and disintegration, as presented in the novel, with the help of the notions of territory, territoriality and rhizome elaborated by Gilles Deleuze and Félix Guattari.
\end{abstract}

\section{KEYWORDS:}

António Lobo Antunes; fiction after Abril 25; Portuguese post-modernism; territoriality; deconstruction of an empire; city; rhizome, rhizomatic city 
As Naus de António Lobo Antunes é uma obra exemplar e paradigmática da literatura pós-25 de Abril que sintetiza em si numa forma directa e complexa tanto as poéticas multifacetadas e heterogéneas, como as políticas eminentes da ficção pós-revolucionária, ou seja do pós-modernismo do romance português. Como o teorético alemão Friedrich Kittler observa, cada período efectua certas transformações no praxis literário mas são poucas as obras que consigam realizar uma mudança radical que atinja a própria estrutura da literatura (Kittler 2012: 119). O romance de António Lobo Antunes, que se pode considerar um ex libris, ou seja, a essência de uma complexa obra de vida, sem qualquer dúvida, insere-se no pequeno grupo daquelas obras que foram capazes de transformar o campo literário nacional, consagrando um novo discurso totalmente autónomo e autopoético.

A antiepopeia antuniana que nas palavras de Maria Alzira Seixo (2002: 176) não é outra coisa de que uma reescrita livre, parcial e carnavelesca da suprema obra camoniana, Os Lusíadas, concentra-se na autodescontrução do grande Império Português justapondo e misturando várias camadas temporais da época das descobertas e dos tempos coloniais com o momento histórico do colapso do mundo imperial. Tendo em conta isto julgo que a representação dos espaços imperiais e coloniais e da redução destes para a antiga metrópole é um motivo fundamental e fulcral do romance, mas não só do romance, senão da literatura e da cultura pós-revolucionária, tal qual. Neste estudo, partindo das particularidades do espaço colonial português e com a ajuda das noções do território e da territorialidade de Gilles Deleuze e Félix Guattari vou tentar demonstrar quais são as consequências do desaparecimento do império colonial e vou argumentar que, na linha do pensamento geofilosófico dos dois pensadores franceses, é mesmo o colapso do território imperial e da narrativa histórica gloriosa que possibilita a emergência da escrita antuniana, num contexto mais vasto da estética textual do pós-modernismo português.

“Todos os impérios são, em grande parte, imaginários ou ficções políticas de nações que se excedem a si mesmas. Um império é, por definição, uma nação que se espalhou por terras longínquas do seu berço inicial e, nessa medida é um território em processo simultâneo de desterritorialização e de reterritorialização" - afirma Margarida Calafate Ribeiro (2004: 27). Esta frase lapidar da investigadora portuguesa constitui o ponto de partida das seguintes considerações. Quanto ao Império Português. podem-se verificar várias características que o distinguem dos outros territórios coloniais, como por exemplo o inglês e o francês que apresentam um esquema mais ou menos homogéneo e análogo, facto detectado e mencionado, embora não estudado por Edward Said no seu livro Culture and Imperialism (1994: xiii). O facto que os modelos colonais dos diferentes poderes colonizadores apresentam um padrão distinto é inquestionável, mas ao mesmo tempo detectam-se certas características dos grandes modelos sólidos (sobretudo o inglês e o francês) que podem ser consideradas mais ou menos universais. Dito isto a pergunta que se coloca é a seguinte: o que é que distingue a colonização portuguesa e o espaço colonial português dos outros grandes modelos consagrados e o que é que faz da empresa colonial portuguesa uma estrutura alternativa comparando com os padrões dominantes? Por primeiro trata-se de um espaço imperial composto por três zonas principais que constituem três eixos históricos de interesse, de dominação cultural e económica: a zona do Oriente, primeiro centro e primeiro coração do Império com os "fumos da Índia"; o Brasil, como autêntico paraíso económico e antropológico, e por fim, o continente africano, onde o sonho da colonização começou com a conquista de Ceuta e onde esse mesmo sonho se desfez graças à guerra colonial 
e à consequente descolonização. A estudiosa acima mencionada, Calafate Ribeiro, no seu livro Uma História de Regressos: Império, Guerra Colonial e Pós-Colonialismo (2004) formula a ideia de que o Império Lusitano de acordo com as mudanças históricas muda o seu centro de interesse. O núcleo central do império, portanto, está em movimento: com o declínio da zona do Oriente depois dos tempos da vanguarda das descobertas, do colonialismo do período manuelino, o império centralizou-se para o Brasil, tentando restabelecer num outro continente o que perdeu no Oriente. Depois da independência da colónia latino-americana que evidentemente significou a mutilação traumatizante do espaço colonial, o conceito imperial tentou recuperarse virando-se para África a partir da segunda parte do século XIX através da ideia ambiciosa do mapa cor-de-rosa. Desta forma o centro do império desloca-se graças à certas circunstâncias histórico-económicas, mas ao mesmo tempo o próprio Império imagina-se como centro, ou seja, apesar da sua posição semiperiférica na ordem mundial, acredita que faz parte da elite das grandes potências económicas, culturais e científicos. Segundo as investigações do sociólogo Boaventura de Sousa Santos, Portugal, desde o declínio da zona colonial do Oriente e a derrota desastrosa de Alcácer-Quibir que forçou a nação à União Ibérica, considera-se um país semiperiférico no sistema mundial capitalista moderno. "Esta condição, sendo a melhor que caracteriza a longa duração moderna da sociedade portuguesa, evoluiu ao longo dos séculos mas manteve os seus traços fundamentais: um desenvolvimento económico intermédio e uma posição de intermediação entre o centro e a periferia da economia-mundo; um Estado que, por ser simultaneamente produto e produtor dessa posição intermédia e intermediária, nunca assumiu plenamente as características do Estado moderno dos países centrais.” (2001: 23-24) Esta complexa e estranha situação semiperiférica implica que Portugal conservou as dicotomias da modernidade (indústria/agricultura, particularidade/universalismo, conservadorismo/ progresso, natureza/técnica, tradição/futuro) num estado primordial e que desde o século XVI desempenhava um papel mediador entre a moderna Europa e o mundo colonial subdesenvolvido. O Império Português é uma entidade semiperiférica, o que quer dizer que nem pertence aos poderes centrais das grandes potências político-económicas do velho continente, e nem faz parte do grupo das nações e colónias subalternas cuja experiência ontológica principal é a periferidade. $\mathrm{Na}$ argumentação de Sousa Santos essa esquisita condição híbrida resultou e reproduziu-se no sistema colonial português.

Mas apesar da sua situação semiperiférica no sistema mundial Portugal imagina-se centro, como se pertencesse à ordem das formações estatais significativas. E essa imagem da centralidade mundial de Portugal, que se produziu graças à noção e ao conceito do grande Império Lusitano que surgiu na época dos Descobrimentos germinando do mito do milagre de Ourique e absorvendo as ideias do Quinto Império e o potencial messianístico do sebastianismo, perdurou até 1974. Em consequência da aventura das Descobertas, espelhada numa forma ostentosa na epopeia camoniana, produziu-se a imagem e a miragem do grande Império Português que durante vários séculos nutria a imaginação cultural e a autopercepção do país. Esta visão e autopercepção ilusória na realidade era "uma visão de Império desligada de um referente histórico para se assumir figura trans-histórica, transcendente e aglutinadora” (Ribeiro, Ferreira 2003: 18).

Não é por acaso que Eduardo Lourenço fala sobre um Império Imaginário com existência imaginária (1994: 11) e António Telo sobre um Império Teórico (1994: 201). Esse carácter 
imaginário ou teórico do Império pode ser considerado a segunda característica marcante do espaço colonial português. Mas a que é que se referem as expressões Império Imaginário e Império Teórico? Referem-se ao facto que aquele grande Império que a nação propagava e visionava não existia mais depois do colapso dos territórios orientais. O apogeu manuelino da história de Portugal foi caracterizado por uma dominação quase absoluta da zona do Oriente, porém os fumos da Índia se evoporaram rapidamente o que implicou que Império para a segunda metade do século XVI tinha perdido a dominação económico-política da referida zona do interesse. Mas apesar dessa não existência do grande Império, dessa falta de existência real daquele antigo Império em que toda a identidade nacional passou a ser baseada, a própria ideia da grandeza imperial mantinha-se na (auto)consciência e na autognose como um certo espaço imaginário, porém "essa grandeza era, concretamente uma ficção" (Lourenço 1978: 25-26). Embora Lourenço não mencione Jacques Lacan quando usa o adjectivo imaginário a propósito do Império Português, no meu ver a referência é clara ao sistema tripartidário do psicanalista francês em que o imaginário (limaginaire) é a segunda categoria de identificação no desenvolvimento do sujeito. No estado de espelho que corresponde à categoria do imaginário o sujeito reconhecese como uma entidade fixa e una através de uma imagem exterior que lhe dá esta sensação ilusória de coesão, unidade, integridade e homogeneidade. Da anti-estrutura caótica do corps morcelé o sujeito chega à identificação, chega à capacidade de formar uma identidade. Mas esse processo de identificação depende sempre de uma certa mediatização, depende sempre duma imagem exterior em que se consegue reconhecer como identidade fixa (Evans 2006: 84-85). Para a identidade nacional de Portugal esta imagem externa é a imagem do Grande Império Lusitano. É nesta narrativa transhistórica em que se reconhece, é esta ilusão ontológica que lhe garante a coesão identitária secular. A obsessão identitária com o Império explica-se com esta problemática do Império Imaginário, enquanto a imagem do Grande Império encontra a sua forma narrativa mais adequada na epopeia camoniana de Os Lusíadas que converte a história em mito e oferece uma visão gloriosa, heróica, grandiosa e jubilosa da expansão, da colonização, da construção do Império e de todo o processo histórico da nação portuguesa. Não é por acaso que o romance de António Lobo Antunes revisita e duma certa forma até reescreve a epopeia camoniana que segundo Eduardo Lourenço, enquanto texto eminentemente sagrado, foi responsável pela elevação da nação portuguesa a um estatuto mítico e deu um corpo mitificado à história de Portugal (2000: 11).

A terceira característica do Império Português e da colonização portuguesa encontramos no conceito ideológico do lusotropicalismo. Portugal sempre enfatizava a diferença da sua colonização e do seu modelo colonial comparando com os outros poderes imperiais. Essa narrativa da colonização alternativa, mais humana e mais humanista, que distinguia sempre o Império Português das outras formações coloniais, encontra finalmente a sua manifestação máxima nas teorias do sociólogo brasileiro Gilberto Freyre e depois na ideologia e na política colonial do Estado Novo. O sistema totalitário que se agarrava à ideia colonial tencionava proteger a sua legitimação sobre as províncias ultramarinas no contexto da política internacional com a ajuda ideológica da teoria do lusotropicalismo.

Tendo em conta toda essa complexidade do particular modelo colonial pode-se afirmar que o Império Português apesar de ter principalmente uma existência imaginária, como Lourenço sugere, é um autêntico território. Um território naqueles vários sentidos em que Deleuze e 
Guattari usam a palavra: geográfica, geofilosófica, espiritual e intelectualmente. O território é uma zona delimitada, um espaço fixo e homogéneo, invadido, dominado e controlado (Parr 2010: 70). É um espaço organizado e regulado por certas leis simbólicas e restrições em que reina um único sistema de significados (Deleuze, Guattari 1994: 182-183). O território tem as suas fronteiras bem definidas, define-se contra o seu exterior, e é uma zona homogénea em que não há espaço para o diálogo, em que predomina a perspectiva do soberano, isto é, da metrópole. O território desta forma é o alicerce e a base da própria identidade, fornecendo continuidade, estabilidade e uma rede bem definida de possibilidades, direcções e significados para uma comunidade e para o sujeito. O território é a zona do simbólico onde as funções, os movimentos, o fluxo do desejo e do pensamento são constrangidos e dominados.

Deleuze e Guattari distinguem duas formas diferentes do pensamento e da representação emprestando dois termos botânicos para descrevê-los: o modelo tradicional que segue a estrutura de uma árvore, portanto, é um modelo linear, homogéneo, estruturado, que se organiza por uma hierarquia fixa e por dicotomias e elementos antagónicos, desenvolve-se segundo as linhas de uma subordinação hierárquica e tem as suas raízes bem fundamentadas que o definem. É o modelo da construção lógica e centralizada, da representação e da percepção objectiva e da sintaxe regular. A outra forma que se opõe ao modelo do pensamento arbóreo é o rizoma. O sistema epistemológico do rizoma caracteriza-se por uma multiplicidade e heterogeneidade orgânicas e por uma construção paratáctica. É um modelo alternativo e essencialmente flexível que não segue nenhuma lógica racional e sistematizadora, senão desenvolve-se paralelamente em várias direcções. Enquanto a construção arbórea baseia-se numa ramificação hierárquia em que cada entidade tem o seu lugar pré-definido e por isso é o terréno da univocidade, do totalitarismo e do despotismo, o modelo rizomático é uma organização descentralizada em que várias entidades, qualidades, sujeitos e objetos se encontram e se entrecruzam num constante movimento, num constante fluxo de devir (devenir) (Deleuze, Guattari 2012: 3-10). Se aplicamos estes modelos epistemológicos para a organização e da percepção do próprio espaço, o território evidentemente pertence à lógica da estrutura hierárquica do modelo arbóreo. O Império, por assim dizer, é um território já em si que possui eo ipso uma certa identidade fixa e uma narrativa histórica que também se organiza segundo a lógica do pensamento arbóreo. A história do território imperial é a História escrita com maiúscula que se encontra dentro do mátrix dum modelo hegeliano segundo a qual não é outra coisa de que a autorrealização gloriosa e o desenvolvimento linear e emancipatória dum sujeito colectivo - Geist, ou substância (Hegel 1988). A História com maiúscula equivale à história imperial e colonial, ou seja, duma perspetiva dialética, supõe-se como uma certa imagem e interpretação unidimensional escrita e inscrita no simbólico da própria perspectiva do poder. A história concebida, produzida e propagada desta forma é a história da ocupação, da colonização e da dominação protagonizada por um sujeito colectivo narcísico, o grande vencedor dos tempos no conceito de Walter Benjamin que aspira para o absoluto e que se contempla numa metanarrativa histórica gloriosa (no caso de Portugal Os Lusíadas). Essa história é a história narrada da perspectiva fixa e central da metrópole em nome duma ordem simbólica e organizadora, é a história do território e da própria territorialização enquanto movimento escatológico e teleológico dum sujeito colectivo, isto é, duma comunidade nacional. Para Hegel a história é sempre inseparável do Estado, ou seja, de um discurso autoconsciente de legitimação simbólica e legal. A construção da narrativa 
histórica, desta forma, é impossível sem a existência de um "legal subject that can serve as the agent, agency, and subject of historical narrative in all of its manifestations” (White 1990: 13). O sujeito que se autorrealiza no processo histórico está intimamente ligado às questões da legitimidade e da narratividade o que significa que a história enquanto modelo total e totalizante é inseparával da autoridade, e deste modo da dominação e da territorialização.

O colapso do Império Português apresentado no romance de Lobo Antunes por um lado inscreve-se naquela lógica imperial que já referi acima, segundo a qual o centro se movimenta. O declínio da zona e da ideia imperial pode ser interpretado como o movimento final, quando o centro volta finalmente para a metrópole e desta forma autodissolve-se no próprio acto de regresso, tornando impossível, como centro organizador, a sustentação e a perpetuação duma narrativa histórica firme e coerente (o que é evidentemente resposável pela mistura e justaposição das camadas temporais e dos respetivos períodos históricos). Por outro lado com a desterritorialização do Império Colonial fecha-se definitivamente o grande ciclo da história imperial. Em consequência do evento subversivo do 25 de Abril, Portugal perde as suas colónias, as suas províncias ultramarinas, deixa de existir como autêntico território imperial, e reduz-se à zona continental. O romance antuniano liga e mistura dois momentos paradigmáticos da história de Portugal: o da partida das caravelas, ou seja o início da expansão, da empresa colonial, da fundamentação do Império, e da territorialização, com o regresso das caravelas - que aliás foi o título original da obra -, isto é, o fim definitivo dessa história imperial enquanto processo territorializante. O grande ciclo glorioso e hegeliano da metanarrativa histórica, que começou com a conquista de Ceuta em 1415, e prolongou-se até 1974, cinco séculos depois dissipa-se, e da êxtase, do ekstasis moderno dos descobrimentos referido por Sloterdijk (2008: 86) fica só um amargo sentimento de derrota histórica. A desterritorialização do Império é o controponto negativo do apogeu do processo autorrealizador do sujeito da história hegeliana, é um evento que faz do grande Império Português um país marginal que falhou o imperativo da modernidade e que não conseguiu cumprir o processo histórico dessa mesma empresa moderna.

No pensamento geofilosófico de Deleuze e Guattari existe uma ligação forte entre as possibilidades do pensamento e a própria terra. Esse tipo de materialismo filosófico sugere que certas formas de pensamento só podem surgir em certas condições geográficas (Deleuze, Guattari 1994). O desaparecimento do território imperial enfrenta Portugal com uma nova situação geográfica, isto é, dum dia para o outro o país encontra-se num estatuto geográfico e geopolítico completamente diferente. O colapso do Império traz consigo o colapso da grande metanarrativa imperial da história gloriosa e heróica que sustentava a identidade colonial e a existência do Império Ultramarino. Portugal, enquanto nação colonizadora passa por uma transformação radical com a revolução de 25 de Abril e com a consequente descolonização. A perda do ideal e do sonho imperial, que durante o sistema totalitário de Salazar estava sintetizado por um lado na imagem do mapa, intitulado Portugal não é um país pequeno, da autoria de Henrique Galvão, e por outro lado no lema ideológico do patriotismo ditatorial Orgulhosamente sós, produz uma certa crise de identidade na cultura portuguesa que passa a ser agravada pela inesperada adesão à União Europeia. A história concebida segundo os princípios hegelianos desta maneira simplesmente se torna impossível graças ao fracasso e à consequente inexistência da metanarrativa legitimadora e organizadora. Assim, "continuities simply dissolve, history becomes no more than a galaxy of current conjuctures, a cluster of eternal presents, wich is to say hardly 
history at all” (Eagleton 1996: 50). No período pós-revolucionário detecta-se por um lado esta situação geopolítica da nação e por um lado a exaustão evidente das duas ideologias dominantes nas décadas anteriores: esgota-se a narrativa política oficial do nacionalismo exacerbado do salazarismo, mas paralelamente também o seu lado oposto, a ideologia marxista da resistência, observam Helena Kaufman e José Ornelas (1994: 145). O colapso destas duas narrativas ideológicas possibilita e provoca uma complexa e radical transformação da ordem do discurso o que possibilita a emergência de um novo epistema político, social, económico e cultural, baseado na negação e na recusa total do Weltanschauung do salazarismo e da visão histórica secular.

Se partimos do antigo topos genêrico, segundo o qual o romance como uma complexa forma literária sempre se insere num determinado contexto socio-económico e político, e sendo inseparável dessa macroestrutura local, reflecte tanto na sua poética como na sua política o estado atual desse contexto histórico, não é surpreendente que a ficção pós-25 de Abril explore constantemente os problemas interligados da identidade, da história e da memória colectiva. O romance pós-25 de Abril absorve "uma vontade de corrigir a imagem do passado português, visível no lançamento de um desafio que consiste no acto de repensar, reformular e transgredir o código simbólico que diz respeito aos portugueses como possuidores de uma história gloriosa." (Sapega 1990-1991: 229).

Tendo em conta as mencionadas premissas geofilosóficas de Deleuze e Guattari a desterritorialização radical, com a perda dum centro ideológico organizador, no meu ver, possibilita a emergência duma nova forma de pensamento com novas formas estéticas, isto é, o triunfo da poética do texto rizomático cujo exemplo máximo é a obra antuniana com As Naus, e que corresponde à estética dum certo pós-modernismo. Aquela forma de pós-modernismo rizomático que se exerce no romance antuniano e em vários outros autores como por exemplo José Saramago, Lídia Jorge, Almeida Faria ou Augusto Abelaira só se tornou possível com a desterritorialização do Império e da narrativa imperial. Embora se detecte uma forte tendência esteticista e desconstrucionista no horizonte do romance português já a partir do fim dos anos 50 que se tinha oposto ao cânone vigente do neo-realismo e cultivava uma desconstrução radical em termos formalistas da estrutura do romance, uma escrita antuniana só se tornou possível com a chegada da condição pós-moderna, enquanto um complexo fenómeno histórico-cultural, caracterizado pela suspeita incondicional perante as grandes narrativas legitimadoras e centralizadoras (Lyotard 1989). O modernismo tardio (designação sugerida por Marcelo G. Oliveira para este período ausente anterior à produção literária pós25 de Abril) dos anos 60 com o seu experimentalismo e com o seu radicalismo dinâmicos começou a desconstrução formalista do romance enquanto construção monolítica e totalizadora, porém, sendo sucessor e hereditário das posturas estéticas do primeiro modernismo português, mostrou-se quase inteiramente apolítico, ou seja, a sua ideologia estética visava só desestablilizar os códigos miméticos e transparentes do neo-realismo e não desestabilizar uma cosmovisão transhistórica (Oliveira 2011: 358-359). “A este propósito, convém não esquecer que em Portugal, tanto por razões políticas (de fechamento e de atraso cultural) como por razões histórico-literárias - refiro-me ao peso normativo do Neo-Realismo e à tardia afirmação da herança modernista e de Pessoa -, a superação do legado modernista demorou a chegar, fosse a partir de uma lógica de continuidade e distanciamento gradual, fosse por ruptura brusca e mesmo iconoclasta." formula Carlos Reis (2005: 8), e temos que acrescentar 
que quando se enfatizam as razões políticas é necessário enfatizar as razões geofilosóficas também. Uma escrita rizomática, de cariz antuniana, com uma determinada poética desconstrucionista que reflecte uma política descontrucionista quanto à cosmovisão histórica tradicional, só se pôde emergir depois da dissipação da grande metanarrativa imperial. A relação entre a (auto)percepção do espaço nacional e as formas estéticas parece ser evidente nesta abordagem geofilosófica.

Mas o que é que acontece com o espaço em As Naus depois da desterritorialização da zona imperial? O grande território ultramarino reduz-se à antiga metrópole que por primeiro implica o desaparecimento completo do mar desta antiepopeia. "A descontrução do sentido da nossa História começa por esta anulação do mar: omiti-lo é omitir os alicerces de um imaginário cultural onde se funda a própria imagem da identidade nacional" - formula Maria das Graças Moreira de Sá (2004: 188). O grande mar das descobertas e da expansão, o mar aberto referido por Luciana Stegagno Picchio (2007), o ambiente principal da história portuguesa desaparece do mundo diegético deste Anti-Lusíadas que pode ser considerado um facto mais do que simptomático. O que fica do Império é a antiga metrópole, Lisboa que já não consegue desempenhar esse papel de ser metrópole, isto é o centro organizador dum vasto espaço. Com o colapso do território Lisboa transforma-se num auténtico rizoma. A construção e a lógica linear e hierárquica do território cede lugar a um espaço essencialmente rizomático. Em vez do território organizado e em consequência compreensível e transparente a diegese desenrola-se numa cidade que reflecte as características do rizoma: é um espaço desorganizado, descentralizado, caótico, a zona da heterogeneidade e da miscigenação absoluta de qualidades, entidades e camadas temporais.

Essa imagem duma capital não transparente e caótica inseparável da sua essência rizomática apresenta-se como um espaço alheio, ameaçador e bizarro ao mesmo tempo, aparece já no segundo romance de António Lobo Antunes, n'Os Cus de Judas. Publicado em 1979, o livro pertence ao primeiro ciclo das obras antunianas, consagrado ao tema e à problemática da guerra colonial, enquanto evento traumatizante que ameaça a integridade do sujeito. A figura do narrador formula a sua opinião sobre a capital portuguesa assim: "O certo é que, à medida que Lisboa se afastava de mim, o meu país, percebe?, se me tornava irreal, o meu país, a minha casa, a minha filha de olhos claros no seu berço, irreais como estas árvores, estas fachadas, estas ruas mortas que a ausência de luz assemelha a uma feira acabada, porque Lisboa, entende, é uma queremesse de província, um circo ambulante montado junto ao rio [...], moramos numa terra que não existe, é absolutamente escusado procurá-la nos mapas porque não existe, está lá um olho redondo, um nome e não é ela" (Antunes 2003: 115). O excerto enfrenta-nos já com aquele problema de percepção do espaço citadino enquanto espaço coeso e transparente que chegará ao seu apogeu em As Naus, romance escrito dez anos mais tarde. Além disso a capital d'Os Cus de Judas já apresenta em si numa forma germinal aquelas características que o Lisboa de As Naus apresentará, nomeadamente um espaço essencialmente irreal, caótico, alheio e unheimlich, com um certo tom carnevalesco (feira, circo ambulante). Michelle Giudicello chama a atenção para a importância da carnavalização (de clara inspiração bakhtiniana) em As Naus (1996: 31-32.) que se revela tanto na relação do romance para com a visão totalizante e hegeliana da história, ou seja na política no texto, como nas próprias formas de narração e na estrutura na obra, isto é, na poética inerente. 
O Lisboa de As Naus é um espaço tão incompreensível e inpenetrável para os moradores como a capital portuguesa descrita pelo narrador d'Os Cus de Judas. "Estávamos sozinhos e postos de banda numa cidade que conhecia sem conhecer" (Antunes 1988: 17) - formula um dos protagonistas. "Ignoro esta cidade, porque ignoro estas travessas e as suas combras ilusórias" (Antunes, 1988, p. 28) - diz a figura central do livro, o homem de nome Luís, a quem falta a vista esquerda, ou seja, uma transfiguração profanizada do poeta maximus Luís de Camões, símbolo do passado glorioso, e da identidade nacional. A cidade é um rizoma mas não naquele sentido positivo, criativo e afirmativo como Deleuze e Guattari sugerem. É um rizoma negativo, um espaço em que não há ordem, não há organização nítida, e este vácuo epistemológico não chega a ser uma qualidade produtiva, senão enche-se duma certa negatividade e privação. É a cidade das "moradas desertas na mágoa" (Antunes 1988: 228) com "prédios em ruína" (Antunes 1988: 226.) onde vive "um rebanho inerte de despaisados" (Antunes 1988: 227). O colapso do território imperial como já mencionei está intimamente ligado ao fracasso da narrativa hegeliana da história. $\mathrm{O}$ que se reconhece nesta Lisboa podre, malcheirosa, cheia de miséria e em ruínas é o já referido conceito da história de Walter Benjamin, sintetizado na imagem dinâmica do Angelus Novus, o anjo da história que se avança para o futuro virando costas para ele e olhando para o passado onde não vê nem autorrealização dialéctica, nem desenvolvimento emancipatório, nem uma narrativa firme e coerente, senão só ruínas, caos e destruição (1971: 82-83). Como Leela Ghandi observa, "If the agents of history fail in every way to achieve recogition in The Return of the Caravels, historicism itself continually disrupted in the novel through the revolutionay action of literature. The "homogenous empty time" that Walter Benjamin once described as the key symptom of historical consciousness is feraciously diversified through the temporal anarchism of Lobo Antunes' anachronistic simultaneity" (2003: 345).

Lisboa pós-revolucionária é uma cidade rizomática representada pela perspetiva desse anjo da história, é um espaço negativo que conserva em si as ruínas do Império e da territorialidade, que está repleta de fantasmas imperiais e de lixo imperial (emprestando a expressão da Ode Marítima de Álvaro de Campos) e que se apresenta como um lugar essencialmente unheimlich para os retornados, os órfãos miseráveis do Império. Como mais uma vez Eduardo Lourenço formula "A ideia óbvia que Portugal acabara de viver o fim de um ciclo histórico impôs-se, menos pela ressonância traumática dos acontecimentos que lhe dão corpo, que pelos problemas imediatos, físicos, que o carregamento e o encargo imprevistos dos retornados suscitaram" (1978: 45). Essa presença física dos retornados passa a ser o problema do espaço citadino no romance. A maioria deles não tem nem emprego nem habitação, por isso a capital torna-se um lugar profundamente unheimlich para eles, unheimlich no sentido original da palavra, ou seja, um lugar não acolhedor que não oferece casa e seguridade para os moradores. "Já não pertenço aqui" (Antunes 1988: 54) - exclama uma das muitas personagens, enquanto um casal de retornados de Guiné num certo ponto da narrativa diz que "Não somos de parte alguma agora" (Antunes 1988: 56). Depois da dissipação do território imperial os retornados não conseguem reterritorializar a antiga metrópole que para eles permanece um rizoma negativo com "uma miséria tranquila" (Antunes 1988: 67). Mas a lógica territorial do colonialismo antigo irremediavelmente reinscreve-se neste rizoma negativo na forma dum capitalismo cruel. Como Maria Alzira Seixo ressalta na sua análise exemplar: “[...] um dos interesses maiores deste livro consiste em sugerir também a dimensão neocolonial que a descolonização portuguesa (como todas as 
outras) implicou, e em inverter papéis de representação »histórica « numa con-versão »fabular « que lhes retira a componente mítica e lhes restitui a grandeza e/ou a fragilidade humana" (2002: 173). Pós-colonialismo e neocolonialismo, destarte, dominam paralelamente o espaço citadino e o mundo inteiro do romance, o que sugere que o mito da revolução libertadora que consiga acabar com o ordo mundis tradicional e estabelecer uma nova ordem democrática fracassou do mesmo modo como as antigas narrativas míticas identitárias. A capital é inundada pela ideologia dum neocolonialismo cruel com o regresso das caravelas. Assim, uma parte significativa dos retornados sofre por uma exploração neocapitalista na cidade ou é responsável por essa mesma exploração. Figuras como Francisco de Xavier e Manuel de Sousa Sepúlveda exercem uma nova forma de dominação urbana sobre as novas massas de cidadãos, os retornados. A Residencial Apóstolo das Índias onde os recém-chegados das colónias procuram hospedar-se e as discotecas da Avenida Almirante Reis tornam-se os lugares autênticos da lógica da capital e da exploração dos oprimidos. Os retornados têm que viver em condições inumanas e pagar uma renda absurda ou, se não dispõem de meios financeiros, têm que deixar as mulheres trabalhar como prostitutas. A cidade como rizoma negativo produz então novas formas de domínio e opressão o que impede os retornados de viver a falta de identidade como algo positivo e afirmativo, por isso sugiro aplicar o termo desimpério para a capital portuguesa em As Naus. Desimpério por causa da falta da identidade imperial e também por produzir novas formas de opressão e exploração que de certa forma originam-se da lógica da relação imperial.

Para concluir podemos afirmar que a construção rizomática da cidade em que várias entidades, espaços e tempos confluem é a própria alegoria do modelo do texto antuniano que sem dúvida se apresenta como o ponto culminante das poéticas do pós-modernismo em Portugal. Um texto que numa anti-estrutura paratáctica e polifónica justapõe vozes, narradores, estilos, camadas temporais, citações da cultura erudita e referências da cultura de massas - um autêntico rizoma deleuziano.

\section{Referências bibliográficas}

Antunes, A. L. (1988). As Naus. Lisboa: Dom Quixote. . (2003). Os Cus de Judas. Lisboa: Dom Quixote.

Benjamin, W. (1971). Tesis de la Filosofia de la Historia. In Angelus Novus (pp. 77-89). Barcelona: Edhasa. Deleuze, G., \& Guattari, F. (1994). What Is Philosophy? New York: Columbia University Press. . (2012). A Thousand Plateaus. London-New York: Bloomsbury.

Eagleton, T. (1996). The Illusions of Postmodernism. Oxford: Blackwell.

Evans, D. (2006). An Introductory Dictionary of Lacanian Psychoanalysis. London-New York: Routledge.

Ghandi, L. (2003). Acts of Literature: Notes on The Return of The Caravels. In E. Cabral, C. J. F. Jorge \& C. Zurbach (Eds.), A Escrita e o Mundo em António Lobo Antunes. Actas do Colóquio Internacional António Lobo Antunes da Universidade de Évora (pp. 339-347). Lisboa: Dom Quixote.

Giudicello, M. (1996) As Naus d'António Lobo Antunes et la carnavalisation de l'histoire oficielle. In M.-H. Piwnik (Ed.), La littérature portugaise. Regards sur deux fins de siécle (XIXe-XXe) (pp. 29-42). Bordeaux: Maison des Pays Ibériques. 
Hegel, G. W. F. (1988). Phänomenologie des Geistes. Hamburg: Félix Meiner Verlag.

Kaufman, H., \& Ornelas, J. (1997). Challenging the Past/Theorizing History: Postrevolutionary Portuguese Fiction. In H. Kaufman \& A. Klobucka (Eds), After the Revolution. Twenty Years of Portuguese Literature 1974-1994 (pp. 145-168). London: Associated University Press.

Kittler, F. A. (2012). Aufschreibesysteme 1800/1900 - Vorwort. Zeitsschrift für Medienwissenschaft, 6, 117126.

Lourenço, E. (1978). O Labirinto da saudade. Lisboa: Dom Quixote.

. (1994). Nós e a Europa ou as duas razões. Lisboa: Imprensa Nacional - Casa da Moeda.

. (2000, Março). Petite mythologie portugaise. Revue des deux mondes, 9-15.

Lyotard, J. F. (1989). A Condição Pós-Moderna. Lisboa: Gradiva.

Oliveira, M. G. (2001). O Período Ausente: Modernismo Tardio na Ficção Portuguesa Contemporânea

(1949-1978). In M. G. Oliveira, \& P. Petrov (Eds.), A Primazia do Texto. Ensaios em Homanagem a Maria Lúcia Lepecki (pp. 347-367). Lisboa: Esfera do Caos.

Parr, A. (2010). The Deleuze Dictionary. Rev. Ed. Edinburgh: Edinburgh University Press.

Picchio, L. S. (2007). Mar Aberto - Viagens dos Portugueses. Lisboa: Caminho.

Ribeiro, M. C. (2004). Uma História de Regressos. Império, Guerra Colonial e Pós-colonialismo. Porto: Edições Afrontamento.

Ribeiro, M. C., \& Ferreira, A. P. (2003). Fantasmas e Fantasias Imperiais no Imaginário Português Contemporâneo. Porto: Campo das Letras Editores.

Reis, C. (2005). A construção do universo ficcional de Lobo Antunes: o mundo como fragmentação. In M.

Ghitescu (Ed.), Colóquio António Lobo Antunes na Roménia, Bucareste (pp. 7-21). Bucuresti: Fundatiei Culturale Memoria.

Sá, M. das G. M. (2004). As duas faces de Jano. Estudos de cultura e literatura portuguesas. Lisboa: IN-CM.

Said, E. (1994). Culture and Imperialism. New York: Vintage Books.

Santos, B. de S. (2001). Entre Prospero e Caliban: Colonialismo, pós-colonialismo e inter-identidade. In M. I. Ramalho \& A. S. Ribeiro (Eds.), Entre Ser e Estar: Raízes, Percursos e Discursos de Identidade (pp. 23-87). Porto: Afrontamento.

Sapega, E. W. (1990-1991). O Romance Pós-Revolucionário Português: Propostas de uma Nova Contrução do Sujeito Nacional. Revista da FCSH, 11, 221-233.

Seixo, M. A. (2002). Os Romances de António Lobo Antunes. Análise, interpretação, resumos e guiões de leitura. Lisboa: Publicações Dom Quixote.

Sloterdijk, P. (2008). Palácio de Cristal. Para uma Teoria Filosófica da Globalização. Lisboa: Relógio d’Água.

Telo, A. (1994). Economia e Império no Portugal Contemporâneo. Lisboa: Edições Cosmos.

White, H. (1990): The Content of the Form. Narrative Discourse and Historical Representation. Baltimore: The Johns Hopkins University Press. 
